\title{
STRA6 Expression Serves as a Prognostic Biomarker of Gastric Cancer
}

\author{
SHUNSUKE NAKAMURA ${ }^{1}$, MITSURO KANDA ${ }^{1}$, DAI SHIMIZU ${ }^{1}$, KOUICHI SAWAKI ${ }^{1}$, \\ CHIE TANAKA ${ }^{1}$, NORIFUMI HATTORI ${ }^{1}$, MASAMICHI HAYASHI ${ }^{1}$, SUGURU YAMADA $^{1}$, \\ GORO NAKAYAMA ${ }^{1}$, KENJI OMAE ${ }^{2}$, MASAHIKO KOIKE ${ }^{1}$ and YASUHIRO KODERA ${ }^{1}$ \\ ${ }^{1}$ Department of Gastroenterological Surgery (Surgery II), \\ Nagoya University Graduate School of Medicine, Nagoya, Japan; \\ ${ }^{2}$ Department of Innovative Research and Education for Clinicians and Trainees (DiRECT), \\ Fukushima Medical University Hospital, Fukushima, Japan
}

\begin{abstract}
Background: Despite advances in our understanding on the pathogenesis of gastric cancer $(G C)$, patients face a poor prognosis. To improve clinical outcomes, effective approaches to diagnosis and treatment employing new diagnostic biomarkers are required to achieve early detection and predict recurrence and prognosis. Materials and Methods: Transcriptome analysis was conducted using surgically resected gastric tissues from four patients with metastatic GC. A total of 228 pairs of primary $G C$ tissues and corresponding normal adjacent tissues were subjected to mRNA expression analysis. To validate our findings, we accessed an integrated microarray dataset and RNA sequencing data of GC cell lines. Results: We identified stimulated by retinoic acid 6 (STRA6) as a differentially overexpressed gene, which encodes a transmembrane protein that mediates the cellular uptake of retinol. To investigate how STRA6 contributes to the malignant phenotype of GC cells, we mined public datasets and found the mRNA encoding retinol binding protein 1 (RBP1), which is associated with retinoid metabolism, was co-expressed with STRA6. Furthermore, STRA6 $m R N A$ levels were significantly higher in GC tissues compared to the corresponding noncancerous adjacent tissues of 228 surgically resected gastric tissue samples. Moreover, patients with high levels of STRA6 mRNA experienced significantly shorter disease-free survival and overall survival. Multivariate analysis revealed that high levels of STRA6 served as a
\end{abstract}

This article is freely accessible online.

Correspondence to: Mitsuro Kanda, MD, Ph.D., Department of Gastroenterological Surgery (Surgery II), Nagoya University Graduate School of Medicine, 65 Tsurumai-cho, Showa-ku, Nagoya 466-8550, Japan. Tel: +81 527442249, Fax: +81 527442255, e-mail: m-kanda@med.nagoya-u.ac.jp

Key Words: Gastric cancer, STRA6, recurrence, prognosis, biomarker. significant risk factor. Conclusion: Patients with high levels of STRA6 mRNA experienced significantly worse clinical outcomes, indicating that STRA6 may serve as a diagnostic and prognostic biomarker of $G C$.

Gastric cancer (GC) is characterized by diverse genomic alterations. The molecular classification of GC described in The Cancer Genome Atlas as well as emerging molecular targeted and immune checkpoint therapy indicate the possibility for developing a genomics-based personalized strategy for treating patients with advanced disease (1-3). Despite advances in our understanding of the pathogenesis of GC, prognosis is poor, mainly due to early asymptomatic lymph node metastasis, leading to incurable hematogenous recurrence $(4,5)$. Further, peritoneal metastasis is difficult to detect when GC recurs (6-8). Therefore, effective diagnostic biomarkers for early detection and prediction of recurrence, as well as for disease prognosis are required $(3,9,10)$.

For this purpose, we herein conducted a transcriptome analysis to identify genes expressed in association with the aggressive phenotype of GC. We focused on stimulated by retinoic acid 6 (STRA6), which was differentially overexpressed in primary GC tissue of patients with metastatic disease, because retinoid metabolism is considered to be involved in carcinogenesis. Previous studies have shown that STRA6 expression is up-regulated in colorectal cancer and ovarian cancer $(11,12)$ although whether it is associated with GC is unknown. We, therefore, aimed to evaluate the clinical significance of STRA6 expression in GC and explored its potential utility for diagnosis and predicting prognosis.

\section{Materials and Methods}

Participants informed consent. This study conformed to the ethical guidelines of the World Medical Association Declaration of Helsinki Ethical Principles for Medical Research Involving Human Subjects and was approved by the Institutional Review Board of Nagoya 
University, Japan (Study Approval Number 2014-0043). Written informed consent for use of clinical samples and data was obtained from all patients.

Transcriptome analysis. Surgically resected gastric tissues from four patients with metastatic GC were subjected to transcriptome analysis. Global expression profiling was conducted using the HiSeq platform (Illumina, San Diego, CA, USA) to compare the expression levels of 57,749 unique mRNAs expressed in primary GC tissues with those of the corresponding noncancerous adjacent gastric mucosa.

Reverse-transcription polymerase chain reaction (RT-PCR) analysis. The levels of STRA6 mRNA in clinical samples were determined in triplicate using RT-PCR analysis as previously described $(13,14)$. The STRA6 primers were as follows: forward 5'-CTATGGCAGCTGGTACATCG-3' and reverse 5'-TACAG GCCGGGTGGTATG-3'. The level of the mRNA encoding glyceraldehyde-3-phosphate dehydrogenase (GAPDH) served as a standard for comparisons. Triplicate samples were subjected to quantitative real-time RT-PCR (qRT-PCR). The expression level of each sample is presented as the amount of the STRA6 amplicon divided by that of GAPDH.

Clinical samples. From 2001 through 2017, 228 pairs of primary GC tissues and corresponding normal adjacent tissues were collected from surgical specimens of patients who underwent curative gastric resection for $\mathrm{GC}$ without neoadjuvant therapy at the Department of gastroenterological surgery, Nagoya University Hospital. Tissue samples were immediately frozen in liquid nitrogen after collection and stored at $-80^{\circ} \mathrm{C}$. Specimens were histologically classified using the Union for International Cancer Control (UICC) classification, seventh edition. Patients were pathologically diagnosed with stages I-III GC, and relevant clinicopathological parameters were acquired from medical records. Since 2006, adjuvant chemotherapy using S-1 (an oral fluorinated pyrimidine) has been administered to all patients with UICC stage II-III gastric cancer, unless contraindicated by the patient's condition (15-17).

Bioinformatic analysis. To validate our experimental data, we accessed an integrated microarray dataset comprising the data of 1,065 patients from three major cancer Research Centers (Berlin, Bethesda, and Melbourne datasets; http://kmplot.com/analysis/). RNA sequencing data of $37 \mathrm{GC}$ cell lines were obtained from the Cancer Cell Line Encyclopedia (https://portals.broadinstitute.org/ccle). We used these datasets to determine the prognostic significance of STRA6 mRNA expression and identify genes that were coordinately expressed with STRA6.

Statistical analysis. Qualitative variables were compared using the $\chi^{2}$ test, and quantitative variables were compared using the MannWhitney test. Disease-free (DFS) and overall survival (OS) rates were calculated using the Kaplan-Meier method, and the difference in survival was analyzed using the log-rank test. We performed multivariate regression analysis with the Cox proportional hazards model to detect prognostic factors, and variables with $p<0.05$ were entered into the final model. To adjust for multiple testing, we employed a false discovery rate (FDR) approach and computed the q-value. Statistical analysis was performed using the JMP 14 software (SAS Institute, Cary, NC, USA) and R version 3.4.1
(Vienna, Austria. URL: http://www.R-project.org/). $p<0.05$ indicates a statistically significant difference.

\section{Results}

Identification of STRA6 as a putative driver of GC. We analyzed the transcriptomes of primary gastric cancer tissues of patients with metastatic GC to identify putative driver genes associated with an aggressive phenotype. We found that 31 genes were differentially expressed at higher levels in GC tissues compared to those of adjacent normal tissues (Table I). We focused on STRA6 because of the association of retinol metabolites with the progression of GC and, to our knowledge, the absence data for STRA6 expression in GC.

Correlation analysis of STRA6 expression using an external dataset. To evaluate the role of STRA6 in cancer progression, we performed correlation analysis using the CCLE dataset to identify genes differentially expressed in association with STRA6. The top five mRNAs with the highest correlation, according to the adjusted false discovery rate (FDR), are listed in Table II. We focused on the gene encoding retinolbinding protein $1(R B P l)$, which serves as a carrier protein involved in the transport of retinol. These data suggest that STRA6 and RBP1, which are related to retinol metabolism, may activate a common signaling pathway leading to gastric carcinogenesis.

Clinical significance of STRA6 expression in surgically resected gastric tissue. The median age of the 228 patients was 67 years (range=26-96 years), and the male:female ratio was 164:64. According to the UICC staging system (seventh edition), 50, 71, and 107 patients exhibited the characteristics of GC pathological stages I, II, and III, respectively. STRA6 mRNA levels were significantly higher in GC tissues compared to those of the corresponding noncancerous adjacent tissues. Moreover, higher levels of STRA6 mRNA were expressed during the late stages of GC (Figure 1A). Patients were assigned according to their median STRA6 mRNA level in GC tissues as follows: high-STRA6 expression group, $\mathrm{n}=114$; low-STRA6 expression group, $\mathrm{n}$ $=114$. The characteristics of two groups are presented in Table III. Most key clinical variables, except the UICC stage, were equally distributed between groups. Higher levels of STRA6 mRNA were significantly associated with shorter DFS and OS [hazard ratio $(\mathrm{HR})=2.27,95 \%$ confidence interval $(\mathrm{CI})=1.29-3.98, p=0.004$; $\mathrm{HR}=3.14,95 \% \mathrm{CI}=1.52$ $6.45, p=0.002$, respectively] (Figure 1B). Multivariate analysis revealed that high levels of STRA6 mRNA had the highest HR among candidate risk factors $(\mathrm{HR}=2.42,95 \%$ CI=1.14-5.13, $p=0.021$ ) (Table IV).

To further investigate the clinical significance of STRA6, we assessed survival rates using the prognostic data acquired 
Nakamura et al: STRA6 Expression as a Prognostic Biomarker of GC

Table I. List of candidate genes expressed at increased levels in primary tumor tissues of patients with metastatic gastric cancer.

\begin{tabular}{|c|c|c|c|c|c|}
\hline Biological function & Symbol & Full name & Location & $\log _{2}$ ratio & $p$-Value \\
\hline \multirow[t]{6}{*}{ Metabolic enzyme } & $P L A 2 G 2 A$ & Phospholipase A2 group IIA & $1 \mathrm{p} 36.13$ & 3.7 & $<0.0001$ \\
\hline & STRA6 & Stimulated by retinoic acid 6 & $15 q 24.1$ & 3.41 & $<0.0001$ \\
\hline & $A K R 1 C 4$ & Aldo-keto reductase family 1 member $\mathrm{C} 4$ & $10 \mathrm{p} 15.1$ & 3.28 & 0.0009 \\
\hline & KLK10 & Kallikrein related peptidase 10 & $19 \mathrm{q} 13.41$ & 3.26 & 0.0003 \\
\hline & PADI2 & Peptidyl arginine deiminase 2 & $1 \mathrm{p} 36.13$ & 3.01 & $<0.0001$ \\
\hline & FKBP 10 & FKBP prolyl isomerase 10 & $17 \mathrm{q} 21.2$ & 2.77 & $<0.0001$ \\
\hline \multirow[t]{3}{*}{ Transcription factor } & $\mathrm{HOXC10}$ & Homeobox $\mathrm{C} 10$ & $12 q 13.13$ & 6.49 & 0.0001 \\
\hline & ELF5 & E74 like ETS transcription factor 5 & $11 \mathrm{p} 13$ & 5 & 0.0001 \\
\hline & $B E X 1$ & Brain expressed X-linked 1 & $\mathrm{Xq} 22.1$ & 3.46 & $<0.0001$ \\
\hline \multirow[t]{2}{*}{ TGF-beta superfamily } & INHBA & Inhibin beta A subunit & $7 \mathrm{p} 14.1$ & 3.76 & $<0.0001$ \\
\hline & INHBB & Inhibin subunit beta $B$ & $2 q 14.2$ & 3.46 & $<0.0001$ \\
\hline \multirow[t]{2}{*}{ Regulator of cell cycle } & CCNE1 & Cyclin E1 & $19 \mathrm{q} 12$ & 3.41 & $<0.0001$ \\
\hline & $C D C 25 B$ & Cell division cycle $25 \mathrm{~B}$ & $20 \mathrm{p} 13$ & 3.17 & 0.0006 \\
\hline \multirow[t]{2}{*}{ Keratin family } & KRT6B & Keratin 6B & $12 \mathrm{q} 13.13$ & 6.83 & 0.0006 \\
\hline & KRT80 & Keratin 80 & $12 \mathrm{q} 13.13$ & 4.29 & 0.0001 \\
\hline \multirow[t]{2}{*}{ Cell adhesive glycoprotein } & THBS4 & Thrombospondin 4 & $5 \mathrm{q} 14.1$ & 4.01 & $<0.0001$ \\
\hline & THBS2 & Thrombospondin 2 & $6 \mathrm{q} 27$ & 3.76 & $<0.0001$ \\
\hline Activator of $\mathrm{G}$ protein signaling & $F N D C 1$ & Fibronectin type III domain containing 1 & $6 \mathrm{q} 25.3$ & 4.5 & $<0.0001$ \\
\hline Adapter of tyrosine kinase receptors & GRB7 & Growth factor receptor bound protein 7 & $17 \mathrm{q} 12$ & 3.98 & $<0.0001$ \\
\hline Cancer antigen & PRAME & Preferentially expressed antigen in melanoma & $22 q 11.22$ & 4.79 & 0.0054 \\
\hline Central nervous neuropeptide & $N P Y$ & Neuropeptide Y & $7 \mathrm{p} 15.3$ & 4.86 & $<0.0001$ \\
\hline Component of tight junction strands & $C L D N 1$ & Claudin 1 & $3 q 28$ & 3.27 & $<0.0001$ \\
\hline Extracellular matrix protein & COMP & Cartilage oligomeric matrix protein & $19 \mathrm{p} 13.11$ & 3.15 & 0.0003 \\
\hline Membrane trafficking protein & SYT7 & Synaptotagmin 7 & $11 \mathrm{q} 12.2$ & 4.29 & $<0.0001$ \\
\hline Neuronal calcium sensor protein & VSNL1 & Visinin like 1 & $2 \mathrm{p} 24.2$ & 4.04 & $<0.0001$ \\
\hline Protein folding and export & DNAJC12 & DnaJ heat shock protein family member $\mathrm{C} 12$ & $10 \mathrm{q} 21.3$ & 4.15 & $<0.0001$ \\
\hline Receptor of G-proteins & $U T S 2 R$ & Urotensin 2 receptor & $17 \mathrm{q} 25.3$ & 4.5 & $<0.0001$ \\
\hline Signal transducer & GNG4 & G protein subunit gamma 4 & $1 \mathrm{q} 42.3$ & 4.84 & $<0.0001$ \\
\hline Specific carrier for retinol & $R B P 4$ & Retinol binding protein 4 & $10 \mathrm{q} 23.33$ & 4.25 & $<0.0001$ \\
\hline Synaptic vesicle exocytosis & $C P L X 2$ & Complexin 2 & $5 q 35.2$ & 4.36 & 0.0007 \\
\hline TNF-receptor & TNFRSF11B & TNF receptor superfamily member $11 \mathrm{~b}$ & $8 \mathrm{q} 24.12$ & 4.57 & $<0.0001$ \\
\hline
\end{tabular}

Table II. List of genes strongly correlated with STRA6 mRNA expression level in GC cell lines.

\begin{tabular}{|c|c|c|c|c|c|}
\hline Symbol & Location & Full name & Biological function & $\mathrm{r}$ & FDR q value \\
\hline$V W A 2$ & $10 \mathrm{q} 25.3$ & $\begin{array}{l}\text { von Willebrand factor A domain } \\
\text { containing } 2\end{array}$ & $\begin{array}{l}\text { von Willebrand factor A } \\
\text { domain-containing protein }\end{array}$ & 0.83 & $<0.0001$ \\
\hline$R B P 1$ & $3 q 23$ & Retinol binding protein 1 & Retinol uptake & 0.8 & $<0.0001$ \\
\hline NKD1 & $16 \mathrm{q} 12.1$ & Naked cuticle homolog 1 & $\begin{array}{l}\text { Negative modulator of the canonical } \\
\text { Wnt } / \beta \text { catenin pathway }\end{array}$ & 0.8 & $<0.0001$ \\
\hline$N A P G$ & $18 p 11.22$ & NSF attachment protein gamma & Synaptic transmission & 0.79 & $<0.0001$ \\
\hline OR $2 J 2$ & $6 \mathrm{p} 22.1$ & $\begin{array}{c}\text { Olfactory receptor family } 2 \\
\text { subfamily } \mathrm{J} \text { member } 2\end{array}$ & G-protein-coupled receptors & 0.78 & $<0.0001$ \\
\hline DEFA5 & $8 \mathrm{p} 23.1$ & Defensin alpha 5 & Antimicrobial and cytotoxic peptides & 0.76 & $<0.0001$ \\
\hline
\end{tabular}

FDR, False discovery rate.

from external validation datasets. A consistent result was observed in the extra-validation cohort of 444 patients with stage I-III GC (Figure 1C). Furthermore, the frequencies of initial recurrence sites, particularly lymph node metastasis, were significantly higher in the high-STRA6 expression group (Figure 2).

\section{Discussion}

Herein we identified STRA6 as a candidate causative gene of GC that was associated with highly malignant tumor cell phenotypes. Moreover, patients with relatively higher levels of STRA6 mRNA in GC tissues $v s$. controls experienced 
A

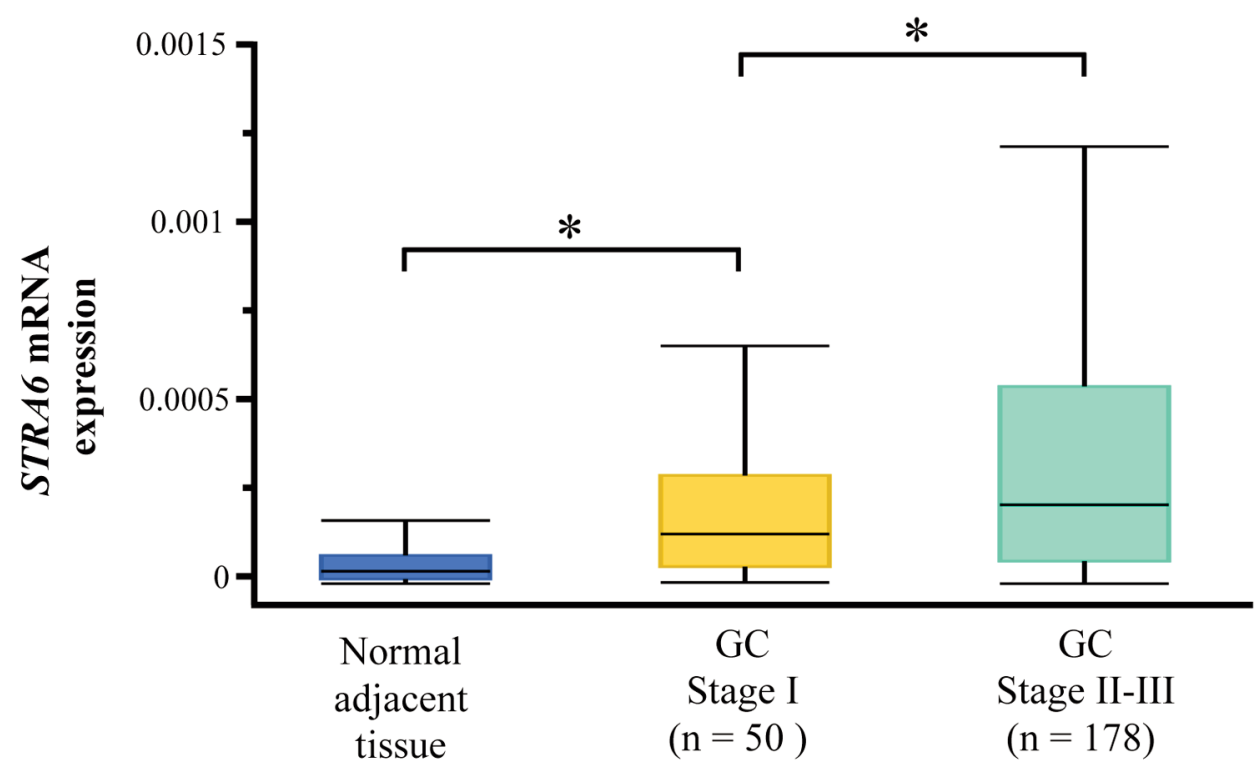

B

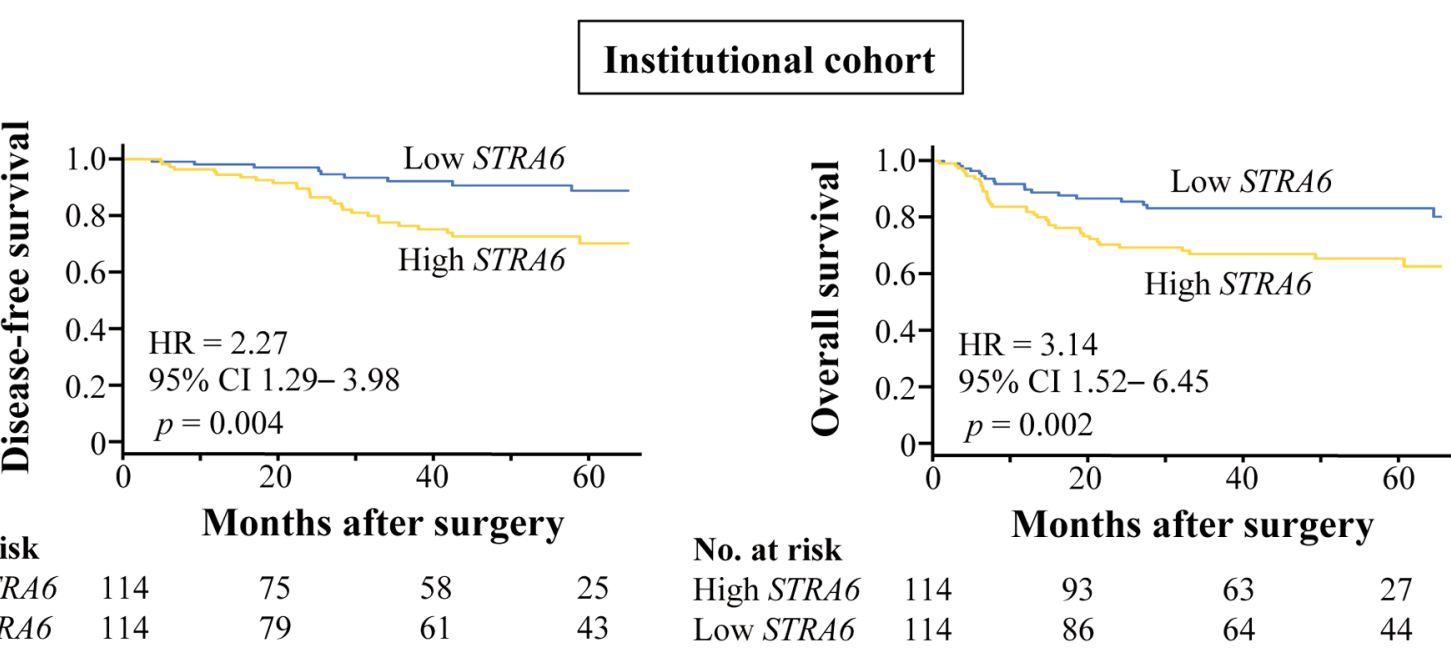

No. at risk

High STRA6

LOW STRA6
114
61
C

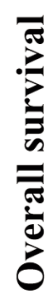

No. at risk

High STRA6

Low STRA6

\section{Extra-validation dataset}

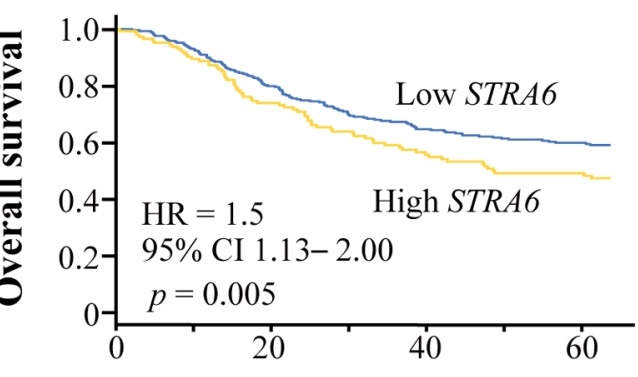

Months after surgery

$\begin{array}{cccc}149 & 95 & 65 & 51 \\ 295 & 218 & 172 & 137\end{array}$

Figure 1. STRA6 mRNA expression in clinical samples and survival analysis. (A) Comparison of STRA6 mRNA levels in normal adjacent tissues and GC tissues according to UICC stage,. * $p<0.05$. (B) KaplanMeier analysis of disease-free survival (DFS) and overall survival (OS) in the institutional cohort. The analyses included 228 patients who underwent curative gastrectomy for stages I-III GC. (C) Kaplan-Meier analysis of $O S$ in the external validation cohort. OS analysis included 444 patients who underwent curative gastrectomy for stages I-III GC. 
Table III. Association between the expression of STRA6 mRNA and clinicopathological parameters of 228 patients with stage I-III gastric cancer.

\begin{tabular}{|c|c|c|c|}
\hline Parameters & $\begin{array}{l}\text { Low STRA6 } \\
\text { expression (n) }\end{array}$ & $\begin{array}{l}\text { High STRA6 } \\
\text { expression (n) }\end{array}$ & $p$-Value \\
\hline \multicolumn{4}{|l|}{ Age (year) } \\
\hline$<65$ & 45 & 53 & \multirow[t]{2}{*}{0.3491} \\
\hline$\geq 65$ & 69 & 61 & \\
\hline \multicolumn{4}{|l|}{ Gender } \\
\hline Male & 79 & 85 & \multirow[t]{2}{*}{0.4613} \\
\hline Female & 35 & 29 & \\
\hline \multicolumn{4}{|c|}{ Body mass index } \\
\hline$<25$ & 93 & 91 & \multirow[t]{2}{*}{0.8669} \\
\hline$\geq 25$ & 21 & 23 & \\
\hline \multicolumn{4}{|c|}{$\mathrm{CEA}(\mathrm{ng} / \mathrm{ml})$} \\
\hline$\leq 5$ & 98 & 96 & \multirow[t]{2}{*}{1.0000} \\
\hline$>5$ & 16 & 16 & \\
\hline \multicolumn{4}{|c|}{ CA19-9 (ng/ml) } \\
\hline$\leq 37$ & 98 & 87 & \multirow[t]{2}{*}{0.2177} \\
\hline$>37$ & 16 & 23 & \\
\hline \multicolumn{4}{|c|}{ Macroscopic type } \\
\hline Type $4 / 5$ & 10 & 11 & \multirow[t]{2}{*}{1.0000} \\
\hline Others & 104 & 103 & \\
\hline \multicolumn{4}{|c|}{ Tumor size $(\mathrm{cm})$} \\
\hline$<6.0$ & 78 & 81 & \multirow[t]{2}{*}{0.7732} \\
\hline$\geq 6.0$ & 36 & 33 & \\
\hline \multicolumn{4}{|c|}{ Tumor location } \\
\hline Lower & 47 & 33 & \multirow[t]{2}{*}{0.0709} \\
\hline Others & 67 & 81 & \\
\hline \multicolumn{4}{|c|}{ UICC pT factor } \\
\hline pT1-3 & 78 & 69 & \multirow[t]{2}{*}{0.2682} \\
\hline $\mathrm{T} 4$ & 36 & 45 & \\
\hline \multicolumn{4}{|c|}{ Differentiation } \\
\hline Poor & 62 & 67 & \multirow[t]{2}{*}{0.5931} \\
\hline Others & 52 & 47 & \\
\hline \multicolumn{4}{|c|}{ Lymphatic involvement } \\
\hline Absent & 23 & 14 & \multirow[t]{2}{*}{0.1501} \\
\hline Present & 91 & 100 & \\
\hline \multicolumn{4}{|c|}{ Vessel invasion } \\
\hline Absent & 46 & 41 & \multirow[t]{2}{*}{0.5857} \\
\hline Present & 68 & 73 & \\
\hline Infiltrative & & & \\
\hline $\mathrm{a} / \mathrm{b}$ & 81 & 77 & 0.6668 \\
\hline $\mathrm{c}$ & 33 & 37 & \\
\hline Lymph nod & & & \\
\hline Absent & 51 & 36 & 0.0560 \\
\hline Present & 63 & 78 & \\
\hline UICC stage & & & \\
\hline I & 33 & 17 & 0.0158 \\
\hline II/III & 81 & 97 & \\
\hline
\end{tabular}

$\chi^{2}$ test. $*$ Statistically significant $(p<0.05$, two-tailed). BMI CEA, Carcinoembryonic antigen; CA19-9, carbohydrate antigen 19-9; UICC, Union for International Cancer Control.

significantly shorter OS. To the best of our knowledge, the present report is the first to implicate STRA6 as a putative oncogene in GC.

STRA6 serves as a cytokine signaling receptor, in addition to its role as a retinol transporter, and activates a
JAK2/STAT3 cascade through retinol uptake and intracellular metabolism, leading to induction of multiple pro-oncogenic STAT target genes (18-20). Karunanithi et al . (12) showed that this STRA6/JAK2/STAT3 signaling cascade is one putative mechanism underlying the tumorigenesis of colon cancer. To investigate the interactions between STRA6 and other proteins that contribute to the malignant phenotype of GC cells, we investigated STRA6 expression using the CCLE datasets, and found that the expression of $R B P 1$ significantly associated with that of STRA6 in GC cell lines. RBP1, which is the intracellular acceptor of retinol, triggers phosphorylation of a tyrosine residue in the cytosolic domain of STRA6, resulting in recruitment and activation of the JAK2 and, in a celldependent manner, the transcription factor STAT3 $(18,19)$. Consequently, RBP1 contributes to activation of the STRA6/JAK2/STAT3 signaling cascade, and triggers inflammation, proliferation, invasion, and angiogenesis. These findings further support the conclusion that STRA6 may participate in GC progression through the JAK2/STAT3 signaling cascade.

We next evaluated the association of STRA6 mRNA levels in GC tissues with patient clinical characteristics. Most clinical variables were equally distributed between the two STRA6-expression groups, except UICC stage. We found that the levels of STRA6 mRNA in GC tissues were significantly higher compared to those of the paired noncancerous tissues. Moreover, the levels of STRA6 mRNA were higher in the cancerous tissues of patients with the later stages of disease. These findings support the conclusion that elevated STRA6 expression may contribute to the initiation and progression of GC.

We observed significant differences between OS and DFS between the two STRA6 expression groups, and patients in the high STRA6 expression group experienced worse outcomes. These clinical findings are consistent with the OS of patients in the external validation dataset. Moreover, multivariate analysis revealed that high levels of STRA6 mRNA served as an independent risk factor of shorter OS. Further, higher levels of STRA6 predicted a higher incidence of recurrence, particularly lymph node metastasis. Considering that the number of patients with metastatic lymph nodes was larger (although the difference was not statistically different), the finding of a higher incidence of lymph node recurrence in the high-STRA6 group was unsurprising. Together, these results support the conclusion that STRA6 mRNA levels will serve as a biomarker for early detection as well as prediction of prognosis and detection of recurrence of GC

Carcinoembryonic antigen and carbohydrate antigen 19-9 are widely employed as biomarkers of GC, $(21,22)$ although our multivariate analysis revealed that elevated levels of these biomarkers were not significantly associated with patient survival. Moreover, the present study indicates that 


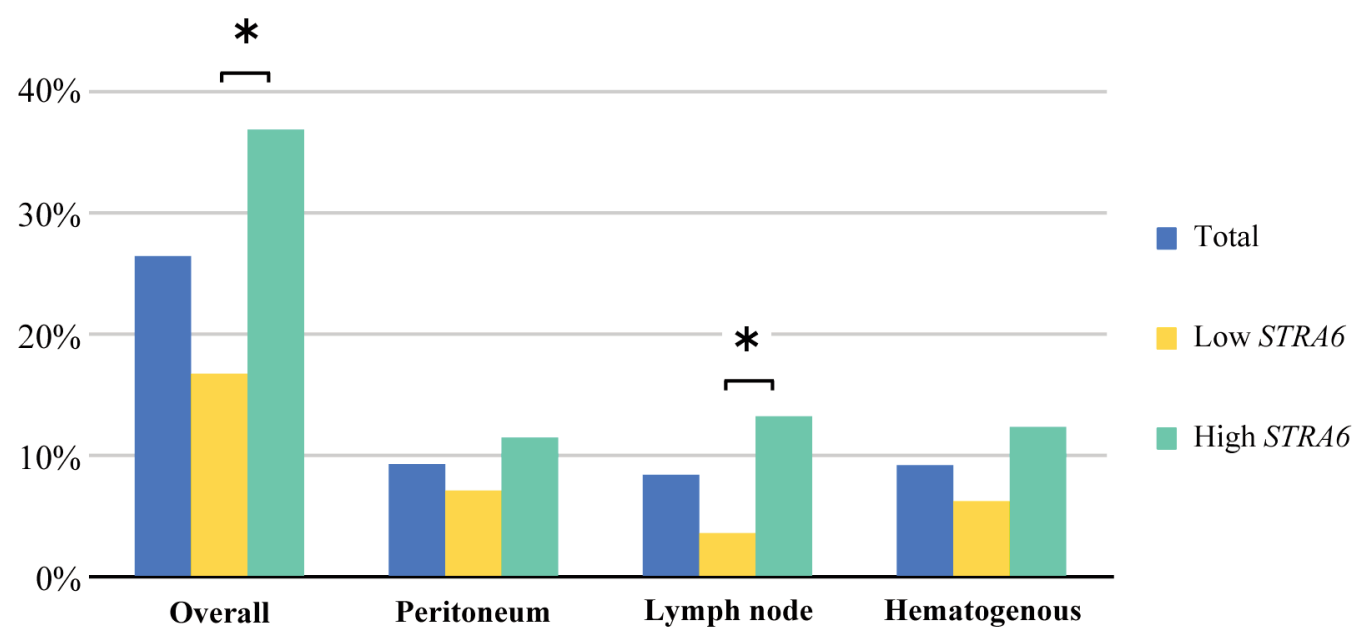

Figure 2. Frequencies of initial recurrence after curative gastrectomy in patients according to STRA6 mRNA levels. * $p<0.05$.

Table IV. Prognostic factors for overall survival of patients with stage I-III gastric cancer $(n=228)$.

\begin{tabular}{|c|c|c|c|c|c|c|c|}
\hline \multirow[t]{2}{*}{ Variable } & \multirow[t]{2}{*}{$\mathrm{n}$} & \multicolumn{3}{|c|}{ Univariate } & \multicolumn{3}{|c|}{ Multivariable } \\
\hline & & Hazard ratio & $95 \% \mathrm{CI}$ & $p$-Value & Hazard ratio & $95 \% \mathrm{CI}$ & $p$-Value \\
\hline Age ( $\geq 65$ year) & 130 & 0.98 & $0.52-1.85$ & 0.949 & 1.20 & $0.61-2.39$ & 0.600 \\
\hline Gender (male) & 164 & 0.94 & $0.47-1.89$ & 0.862 & 1.26 & $0.59-2.69$ & 0.553 \\
\hline Body mass index $(\geq 25)$ & 44 & 0.85 & $0.37-1.93$ & 0.697 & & & \\
\hline CEA $(\geq 5 \mathrm{ng} / \mathrm{ml})$ & 32 & 1.43 & $0.63-3.25$ & 0.394 & & & \\
\hline CA19-9 ( $\geq 37 \mathrm{ng} / \mathrm{ml})$ & 39 & 2.61 & $1.28-5.32$ & 0.008 & 1.64 & $0.77-3.48$ & 0.199 \\
\hline Macroscopic type (4/5) & 21 & 1.90 & $0.79-4.54$ & 0.148 & & & \\
\hline Tumor size $(\geq 6.0 \mathrm{~cm})$ & 69 & 2.64 & $1.41-4.95$ & 0.003 & 2.09 & $1.07-4.08$ & 0.031 \\
\hline Tumor location (lower) & 80 & 0.73 & $0.37-1.44$ & 0.364 & & & \\
\hline UICC $\mathrm{T}$ factor (T4) & 81 & 3.44 & $1.80-6.57$ & $<0.001$ & 1.68 & $0.71-3.98$ & 0.242 \\
\hline Differentiation (poor) & 129 & 1.73 & $0.89-3.37$ & 0.107 & & & \\
\hline Lymphatic involvement (present) & 191 & 5.08 & $1.22-21.18$ & 0.026 & 0.42 & $0.07-2.45$ & 0.335 \\
\hline Vessel invasion (present) & 141 & 3.48 & $1.59-7.61$ & 0.002 & 2.25 & $0.91-5.55$ & 0.077 \\
\hline Infiltrative growth (c) & 70 & 2.12 & $1.12-4.02$ & 0.021 & 1.64 & $0.77-3.49$ & 0.195 \\
\hline Lymph node metastasis (present) & 141 & 11.46 & $3.50-37.52$ & $<0.001$ & 3.78 & $0.77-18.68$ & 0.103 \\
\hline UICC stage (stage III) & 108 & 7.08 & $3.12-16.08$ & $<0.001$ & & & \\
\hline Adjuvant chemotherapy (performed) & 106 & 1.37 & $0.73-2.58$ & 0.323 & 2.36 & $0.70-7.97$ & 0.168 \\
\hline STRA6 (high) & 114 & 3.13 & $1.52-6.45$ & 0.002 & 2.42 & $1.14-5.13$ & 0.021 \\
\hline
\end{tabular}

CEA, Carcinoembryonic antigen; CA19-9, carbohydrate antigen 19-9; UICC, Union for International Cancer Control; STRA6, stimulated by retinoic acid 6. Bold values indicate statistical significance.

the assessment of STRA6 mRNA levels in surgically resected GC tissue, or biopsy specimens obtained from preoperative endoscopic investigations, may provide prognostic information about patients with GC. We, therefore, recommend that patients with high levels of STRA6 mRNA should be considered as candidates for undergoing enhanced perioperative chemotherapy.

There are several limitations to the present study. First, we analyzed data acquired from a small number of patients treated at a single Institution. However, we found that our analysis of an external validation dataset was consistent with that of our patients. Further, the cut-off value of STRA6 levels and the sensitivity and specificity of detection require further optimization. Second, information about chemotherapy was unavailable, because the study's subjects were acquired over a long period during which the chemotherapeutic regimen was progressively updated. It is important to note that neoadjuvant chemotherapy is not a standard treatment for GC in Japan. Third, direct functional analyses of STRA6 were not conducted herein. Molecular genetics techniques such as 
RNA interference, transgenic expression of STRA6, and CRISPR/Cas9 mutagenesis will likely lead to a better understanding of the underlying mechanism of the effects of STRA6 on the pathobiology of GC. Our study provides compelling evidence that the JAK2/STAT3 cascade contributes to STRA6-mediated tumor progression. Nevertheless, further research is required to decipher the signal transduction pathways that mediate the putative oncogenic effects of STRA6 on gastric epithelial cells.

In conclusion, patients with high levels of STRA6 mRNA experienced significantly worse clinical outcomes, indicating that STRA6 may serve as diagnostic and prognostic biomarker of GC.

\section{Conflicts of Interest}

The Authors have no conflicts of interest with regard to the present study.

\section{Authors' Contributions}

SN and MK conceived the study concept and design, analysed data and wrote the manuscript. MK, DS, MK and YK contributed to data acquisition and interpretation. KO contributed to statistical analysis. CT, NH, MH, SY, GN and YK revised the draft. All Authors have read and approved the final version of the manuscript.

\section{References}

1 Figueiredo C, Camargo MC, Leite M, Fuentes-Panana EM, Rabkin CS and Machado JC: Pathogenesis of gastric cancer: Genetics and molecular classification. Curr Top Microbiol Immunol 400: 277-304, 2017. PMID: 28124158. DOI: 10.1007/978-3-319-50520-6_12

2 Katona BW and Rustgi AK: Gastric cancer genomics: advances and future directions. Cell Mol Gastroenterol Hepatol 3(2): 211217, 2017. PMID: 28275688. DOI: 10.1016/j.jcmgh.2017.01.003

3 Nakamura S, Kanda M and Kodera Y: Incorporating molecular biomarkers into clinical practice for gastric cancer. Expert Rev Anticancer Ther 19(9): 757-771, 2019. PMID: 31437076. DOI: 10.1080/14737140.2019.1659136

4 Umeda S, Kanda M, Miwa T, Tanaka H, Tanaka C, Kobayashi D, Hayashi M, Yamada S, Nakayama G, Koike M and Kodera Y: Fraser extracellular matrix complex subunit 1 promotes liver metastasis of gastric cancer. Int J Cancer 146: 2865-2876, 2019. PMID: 31597194. DOI: 10.1002/ijc.32705

5 Kanda M, Tanaka H, Shimizu D, Miwa T, Umeda S, Tanaka C, Kobayashi D, Hattori N, Suenaga M, Hayashi M, Iwata N, Yamada S, Fujiwara M and Kodera Y: SYT7 acts as a driver of hepatic metastasis formation of gastric cancer cells. Oncogene 37(39): 5355-5366, 2018. PMID: 29858600. DOI: 10.1038/s41388-0180335-8

6 Kanda M, Shimizu D, Tanaka H, Tanaka C, Kobayashi D, Hayashi M, Takami H, Niwa Y, Yamada S, Fujii T, Sugimoto H and Kodera Y: Synaptotagmin XIII expression and peritoneal metastasis in gastric cancer. Br J Surg 105(10): 1349-1358, 2018. PMID: 29741294. DOI: $10.1002 /$ bjs. 10876
7 Nakanishi K, Kanda M, Umeda S, Tanaka C, Kobayashi D, Hayashi M, Yamada S and Kodera Y: The levels of SYT13 and CEA mRNAs in peritoneal lavages predict the peritoneal recurrence of gastric cancer. Gastric Cancer 22(6): 1143-1152, 2019. PMID: 31055693. DOI: 10.1007/s10120-019-00967-3

8 Kanda M, Shimizu D, Tanaka H, Tanaka C, Kobayashi D, Hayashi M, Iwata N, Niwa Y, Yamada S, Fujii T, Sugimoto H, Murotani K, Fujiwara M and Kodera Y: Significance of SYT8 for the detection, prediction, and treatment of peritoneal metastasis from gastric cancer. Ann Surg 267(3): 495-503, 2018. PMID: 28026832 DOI: 10.1097/SLA.0000000000002096

9 Kanda M, Suh YS, Park DJ, Tanaka C, Ahn SH, Kong SH, Lee HJ, Kobayashi D, Fujiwara M, Shimada H, Cho B, Murotani K, Kim HH, Yang HK and Kodera Y: Serum levels of ANOS1 serve as a diagnostic biomarker of gastric cancer: A prospective multicenter observational study. Gastric Cancer 23: 203-211, 2019. PMID: 31377880. DOI: 10.1007/s10120-019-00995-Z

10 Virgilio E, Proietti A, D'Urso R, Cardelli P, Giarnieri E, Giovagnoli MR, Montagnini M, Villani S, Balducci G and Cavallini M: Elevated gastric juice carbohydrate antigen 72.4 (Ca 72.4) is an independent prognostic factor of poor survival for gastric cancer patients. Anticancer Res 40(3): 1691-1695, 2020. PMID: 32132076. DOI: 10.21873/anticanres.14121

11 Szeto W, Jiang W, Tice DA, Rubinfeld B, Hollingshead PG, Fong SE, Dugger DL, Pham T, Yansura DG, Wong TA, Grimaldi JC, Corpuz RT, Singh JS, Frantz GD, Devaux B, Crowley CW, Schwall RH, Eberhard DA, Rastelli L, Polakis P and Pennica D: Overexpression of the retinoic acid-responsive gene Stra6 in human cancers and its synergistic induction by Wnt-1 and retinoic acid. Cancer Res 61(10): 4197-4205, 2001. PMID: 11358845.

12 Karunanithi S, Levi L, DeVecchio J, Karagkounis G, Reizes O, Lathia JD, Kalady MF and Noy N: RBP4-STRA6 pathway drives cancer stem cell maintenance and mediates high-fat dietinduced colon carcinogenesis. Stem Cell Reports 9(2): 438-450, 2017. PMID: 28689994. DOI: 10.1016/j.stemcr.2017.06.002

13 Uno Y, Kanda M, Miwa T, Umeda S, Tanaka H, Tanaka C, Kobayashi D, Suenaga M, Hattori N, Hayashi M, Yamada S, Nakayama G, Fujiwara M and Kodera Y: Increased expression of DNAJC12 is associated with aggressive phenotype of gastric cancer. Ann Surg Oncol 26(3): 836-844, 2019. PMID: 30617870. DOI: $10.1245 / \mathrm{s} 10434-018-07149-\mathrm{y}$

14 Umeda S, Kanda M, Koike M, Tanaka H, Miwa T, Tanaka C, Kobayashi D, Suenaga M, Hayashi M, Yamada S, Nakayama G and Kodera Y: Copine 5 expression predicts prognosis following curative resection of esophageal squamous cell carcinoma. Oncol Rep 40(6): 3772-3780, 2018. PMID: 30272363. DOI: 10.3892/or.2018.6742

15 Japanese Gastric Cancer A: Japanese gastric cancer treatment guidelines 2014 (ver. 4). Gastric Cancer 20(1): 1-19, 2017. PMID: 27342689. DOI: 10.1007/s10120-016-0622-4

16 Nakanishi K, Kanda M, Ito S, Mochizuki Y, Teramoto H, Ishigure K, Murai T, Asada T, Ishiyama A, Matsushita H, Tanaka C, Kobayashi D, Fujiwara M, Murotani K and Kodera Y: Delay in initiation of postoperative adjuvant chemotherapy with S-1 monotherapy and prognosis for gastric cancer patients: Analysis of a multi-institutional dataset. Gastric Cancer 22(6): 1215-1225, 2019. PMID: 30955110. DOI: 10.1007/s10120-019-00961-9

17 Kanda M, Murotani K, Kobayashi D, Tanaka C, Yamada S, Fujii T, Nakayama G, Sugimoto H, Koike M, Fujiwara M and Kodera 
Y: Postoperative adjuvant chemotherapy with S-1 alters recurrence patterns and prognostic factors among patients with stage II/III gastric cancer: A propensity score matching analysis. Surgery 158(6): 1573-1580, 2015. PMID: 26120068. DOI: 10.1016/j.surg.2015.05.017

18 Noy N: Vitamin a transport and cell signaling by the retinolbinding protein receptor STRA6. Subcell Biochem 81: 77-93, 2016. PMID: 27830501 DOI: 10.1007/978-94-024-0945-1_3

19 Berry DC, Levi L and Noy N: Holo-retinol-binding protein and its receptor STRA6 drive oncogenic transformation. Cancer Res 74(21): 6341-6351, 2014. PMID. 25237067. DOI: 10.1158/00085472.CAN-14-1052

20 Carrera S, Cuadrado-Castano S, Samuel J, Jones GD, Villar E, Lee SW and Macip S: Stra6, a retinoic acid-responsive gene, participates in p53-induced apoptosis after DNA damage. Cell Death Differ 20(7): 910-919, 2013. PMID: 23449393. DOI: $10.1038 / \mathrm{cdd} .2013 .14$
21 Kanda M, Murotani K, Tanaka H, Miwa T, Umeda S, Tanaka C, Kobayashi D, Hayashi M, Hattori N, Suenaga M, Yamada S, Nakayama G, Fujiwara M and Kodera Y: Integrated multigene expression panel to prognosticate patients with gastric cancer. Oncotarget 9(27): 18775-18785, 2018. PMID: 29721160. DOI: 10.18632/oncotarget.24661

22 Kanda $\mathrm{M}$ and Kodera Y: Recent advances in the molecular diagnostics of gastric cancer. World J Gastroenterol 21(34): 98389852, 2015. PMID: 26379391. DOI: 10.3748/wjg.v21.i34.9838

Received April 15, 2020

Revised May 20, 2020

Accepted May 29, 2020 